\title{
O significado da maternidade na trajetória de três jovens mães: um estudo psicanalítico
}

\section{The meaning of motherhood for three young mothers:}

\author{
A psychoanalytic study
}

Kate Delfini SANTOS ${ }^{1}$

Ivonise Fernandes da MOTTA ${ }^{1}$

\begin{abstract}
Resumo
O objetivo desse artigo é apresentar o significado da experiência da maternidade na trajetória de três jovens mães. As participantes se encontravam em um abrigo para mães adolescentes no município de São Paulo, São Paulo. Foram realizados cinco encontros com cada dupla, formada por mãe e filho, a fim de compreender a experiência de cada mãe em relação à gestação e à maternidade, a experiência com as diversas formas de violência e o vínculo com o filho. Os conteúdos encontrados se articulam com as ideias do psicanalista Donald W. Winnicott. Nos três casos analisados, observamos que a maternidade tem um significado especial e revela-se como sinal de esperança, segundo a conceituação de Winnicott, de reencontrar uma experiência de afeto significativa, por meio da qual se constitua um sentimento autêntico de preocupação e comprometimento com o próximo. No entanto, deixar as mães à própria sorte nesse momento as coloca em uma situação de risco para a repetição de abandono e violência vivenciados.
\end{abstract}

Palavras-chave: Gravidez na adolescência; Psicanálise; Relação mãe-criança; Teoria de Winnicott; Violência.

\begin{abstract}
The aim of this paper is to describe the meaning of the experience of motherhood for three young mothers. The participants were staying in a shelter for teenage mothers in the city of São Paulo. Five meetings were conducted with each pair (mother and child), with the aim of understanding each mother's experience in relation to pregnancy and motherhood, various forms of violence and the bond with their child. The contents found were related to ideas presented by the psychoanalyst Donald W. Winnicott. In all three cases analyzed, we observed that motherhood has a special meaning and is considered a sign of hope, according to Winnicott's concept of rediscovering a significant experience of affection, upon which a genuine feeling of concern and commitment for the other can be grounded. However, if mothers are left to their own fate at this moment, there is a risk that experiences of neglect and violence may be repeated.
\end{abstract}

Keywords: Adolescent pregnancy; Psychoanalysis; Mother-child relation; Winnicott theory; Violence.

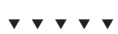

1 Universidade de São Paulo, Instituto de Psicologia, Departamento de Psicologia Clínica. Cidade Universitária, Av. Prof. Mello Moraes, 1721, Bloco F, 05508-030, São Paulo, SP, Brasil. Correspondência para/Correspondence to: I.F. MOTTA. E-mail: <lapecri@usp.br>.

Artigo elaborado a partir da dissertação de K.D. SANTOS, intitulada "Um estudo psicanalítico sobre a maternidade na adolescência: histórias de abandono, violência e esperança na trajetória de três jovens mães”. Universidade de São Paulo, 2011. 
A relação mãe-filho é um dos elementos fundadores do psiquismo humano, e é por meio desta que a criança apreende o mundo a sua volta. São muitas as variáveis que interferem nessa relação, como, por exemplo, a experiência pessoal, os legados inter e transgeracionais, as condições históricas, sociais e econômicas.

A gravidez durante a fase adolescente vem sendo estudada por várias áreas do conhecimento; geralmente, é referida como um problema (Yazlle, 2006), e, quase sempre, apontada como uma questão das classes menos favorecidas economicamente.

Na área da saúde, os problemas são referidos devido ao índice de prematuridade e baixo peso do bebê ao nascer, entre outros (Goldenberg, Figueiredo, \& Silva, 2005; Suzuki, Ceccon, Falcão, \& Vaz, 2007); no âmbito social, pelas consequências que acarreta na vida da jovem após o nascimento da criança, como a evasão escolar, a dificuldade em se empregar e a perpetuação da pobreza (Gama, Szwarcwald, \& Leal, 2002; Oliveira, 1999); na área da saúde mental, devido à imaturidade emocional da jovem para assumir a função parental (Sabroza, Leal, Souza Jr., \& Gama, 2004).

No entanto, algumas pesquisas têm buscado compreender a gravidez durante a adolescência de forma menos estigmatizante, abordando a questão com mais profundidade para apreender o seu significado, o que tem proporcionado um conhecimento muito rico sobre o tema, menos reducionista, e oferecido uma visão do ser humano em sua totalidade.

No estudo realizado por Gontijo e Medeiros (2008) com mães adolescentes em situação de abrigamento, a experiência da maternidade possibilitou-Ihes organizar suas vidas a partir das necessidades dos filhos, o que se revela como uma conquista dessas meninas, visto que, nas ruas, onde se encontrava a maioria delas, a falta de limites, de horários e de regras prevalece. Os autores ressaltam ainda que a satisfação das mães estava principalmente relacionada à formação de um vínculo de afeto genuíno com o filho.

A adolescência é uma fase permeada por períodos de ambivalência e instabilidade dos senti518 mentos e das emoções, de reestruturação da ima- gem corporal e egoica, e, por isso, uma gravidez nessa fase é sempre classificada como um risco para a criança. No entanto, a necessidade de constituir uma família e de experienciar a parentalidade vai ser buscada repetidas vezes por aqueles que necessitam superar o abandono anterior, o vazio, a ausência de relações de afeto. Para alguns, o fato de estar na posição de cuidador possibilita o estabelecimento de um lugar e de uma função social; para outros, é um peso maior do que se pode suportar e a ambivalência toma conta da relação de maneira que fica quase impossível exercer a função de pai ou de mãe. Há espaços no mundo interno desses jovens que precisam ser preenchidos; há vazios criados pelo mundo adulto e pela sociedade, que falha em dar continência às demandas e às necessidades dos indivíduos.

\section{Parentalidade, transmissão psíquica e a questão do amor materno}

A maternidade, considerada no senso comum como instinto natural da mulher, uma vocação para cuidar e amar incondicionalmente o filho, é um assunto polêmico. Muitas são as críticas à visão de que esse amor é inato e sobre a existência de um instinto maternal. Badinter (1985) faz um detalhado percurso histórico sobre essa questão e escreve a respeito da indiferença e da frieza dos pais em relação aos filhos até o século 18 . Em seu livro "O amor conquistado: o mito do amor materno", ela defende a tese de que o que muitos autores chamam de instinto materno não passa de uma construção sociopolítica que se modifica de tempos em tempos. Ressalta ainda a questão de gênero e a subordinação da mulher - que teve sua função definida por meio da maternidade durante séculos -, em relação ao homem. Entretanto, a mesma autora, em um de seus capítulos, afirma que o desinteresse pela criança era também uma maneira de os pais defenderem-se do sofrimento pela perda de um filho, o que era muito comum até o fim do século 18, devido aos altos índices de mortalidade infantil. "Se a mãe se apegasse intensamente a cada um de seus bebês, sem dúvida morreria de dor" (Badinter, 1985, p.85). 
Dolto (1984) também reconstitui a história sobre o amor materno em seu texto " $A$ gênese do sentimento materno: esclarecimento psicanalítico da função simbólica feminina". A autora apresenta a ideia de que o sentimento materno é fruto de uma construção das relações estabelecidas entre a menina e suas referências femininas e de como ocorreu seu processo de desenvolvimento emocional no que se refere à castração. Além disso, o amor materno dá suporte ao narcisismo do indivíduo que se percebe investido pelo afeto e desejo do outro, por isso a necessidade humana em atribuir à genitora características tão dóceis e de abdicação por outros interesses que não seja o de ser mãe.

Do mesmo modo, a construção da paternidade também pode ser entendida a partir das identificações que o menino irá realizar com o pai, com outras figuras masculinas, da maneira como vivenciou a relação triangular edipiana e de acordo com o grupo e a cultura em que está inserido. Ou seja, pode-se pensar que a maneira pela qual uma mulher exerce seu papel materno e o homem exerce a paternidade esteja relacionada às vivências que ambos tiveram como filhos e à qualidade dos cuidados que receberam, às características atribuídas aos papéis materno e paterno na cultura, bem como às resoluções de seus conflitos edípicos. Ao exercerem essas funções, de mãe e pai, entram em um campo importante para a formação da personalidade do ser humano, que é o exercício da parentalidade e da transmissão inter e transgeracional (Lebovici, 2004).

Lebovici (2004), no "Diálogo com Letícia Solis-Ponton", afirma que "a noção de parentalidade não inclui apenas o sentido biológico do termo: ser pai ou mãe não é só ter um filho, mas também uma oportunidade para refletir a respeito de sua descendência" (p.21). Assim, a própria história e a história das gerações anteriores têm grande influência em todo o processo da maternidade e da paternidade. Essas histórias são contadas em cada detalhe da relação pais-filhos sob a forma dos cuidados que oferecem, das expectativas que criam e dos conflitos e sintomas que aparecem.

A transmissão psíquica é descrita por Paiva e Gomes (2008) como histórias familiares herdadas que estão presentes na formação do psiquismo. A maneira como cada indivíduo recebe essa herança e torna-se ou não prisioneiro dela depende da possibilidade de elaboração desses conteúdos.

Correa (2000) aponta dois tipos de transmissão, que estão interligados, e os distingue da seguinte maneira:

a) Intergeracional: inclui um espaço de meta-
bolização do material psíquico transmitido
pela geração mais próxima e que, transfor-
mado, passará à seguinte. b) Transgera-
cional: referida a um material psíquico da
herança genealógica não transformada e
não simbolizada que apresenta lacunas e
vazios na transmissão; o significado aponta
para o fato psíquico inconsciente que atra-
vessa diversas gerações (p.65).

A parentalização ocorre se há recursos internos nos futuros pais para tal, inclusive durante a gravidez, na medida em que representa os investimentos que se faz em relação ao filho. A qualidade desse processo também apresenta uma variável como representante de um investimento narcísico dos pais na constituição de um filho e, por isso, a história pessoal deles irá ter influência direta na expectativa em relação a esse filho. Existe a necessidade de uma reorganização interna que permita a essa criança um lugar e possibilite um sentimento de pertencimento. Porém, segundo Lebovici (2004):

...se os pais não trabalharam o desejo da
criança, o recém-nascido vai reivindicar a sua
função de parentalizar e pode ser que ele
tenha de afrontar a recusa dos pais. A criança
se expressa por meio de gestos que a sua
mãe interpreta levando em conta seu histó-
rico familiar (p.22).

Winnicott (1958/2000) aponta que algumas mulheres podem ter dificuldade em desempenhar a função materna e entrar em um estado psíquico especial, que ele denominou "preocupação materna primária". Sobre esse estado, ele escreve:

Gradualmente, esse estado passa a ser o de uma sensibilidade exacerbada durante e principalmente ao final da gravidez. Sua duração é de algumas semanas após o 
nascimento do bebê.Dificilmente as mães o recordam depois que o ultrapassaram.Eu daria um passo a mais e diria que a memória das mães a esse respeito tende a ser reprimida (p.401).

Trata-se de um momento especial, de fundamental relevância na construção do psiquismo, em que a mãe regride e volta-se exclusivamente para o bebê, retirando temporariamente seu interesse do social. A preocupação materna primária possibilita à mãe adaptar-se às necessidades de seu bebê, respondendo adequadamente às suas demandas, de modo que ele passe a confiar no meio. No entanto, Winnicott (1958/2000) afirma que esta não é uma habilidade inata a todas as mulheres ou, ainda, pode apresentar-se na experiência com um filho, mas não com outro. Isso nos faz pensar que o momento e a situação em que a gravidez ocorre são de extrema relevância para que a mãe possa desenvolver esse aspecto em potencial de sua personalidade. Além disso, Winnicott (1966/2006) chama atenção para o fato de que a mãe "também já foi um bebê, e traz com ela as lembranças de tê-lo sido; tem, igualmente, recordações de que alguém cuidou dela, e essas lembranças tanto podem ajudá-la quanto atrapalhá-la em sua própria experiência como mãe" (p.4). O desenvolvimento dessa capacidade de adaptação pode ser uma conquista, e a mãe também precisa de um ambiente acolhedor e facilitador, até mesmo para que ela possa voltar seu interesse e seu afeto inteiramente para o filho.

Sendo assim, uma mulher pode enfrentar problemas para desempenhar a função materna e oferecer a sustentação, o holding, necessário ao seu bebê para que ele se desenvolva e integre aspectos de sua personalidade.

O holding é uma das principais funções maternas e implica: protegê-lo da agressão fisiológica; dar conta da sensibilidade cutânea do bebê - tato e temperatura -, sensibilidade auditiva, sensibilidade visual, sensibilidade à queda; incluir a rotina completa do cuidado dia e noite; acompanhar as mudanças do dia a dia, que fazem parte do desen520 volvimento do bebê.
Ao descrever aspectos do cuidado materno, Winnicott (1960/1990) ressalta que o suporte oferecido pelo ambiente não é um trabalho mecânico, mas implica empatia materna: "O holding inclui especialmente o holding físico do lactente, que é uma forma de amar" (p.48).

Outras duas funções do cuidado materno são: 1) manipular (handling) e 2) apresentar objetos ou "realização". A primeira facilita a integração psicossomática, possibilitando à criança gozar a experiência do funcionamento corporal e de ser. A segunda dá início à capacidade de o bebê relacionar-se com objetos, o que desenvolve ainda mais sua capacidade para sentir-se real em sua relação com o mundo externo.

Brazelton (1988) afirma que:

O apego e os cuidados parentais não são simplesmente temas relacionados aos cuidados, mas também aos processos de aprendizado sobre como lidar com a cólera, a frustração, o desejo de fugir do papel e, mesmo, de abandonar a criança. Aprender a viver com estes sentimentos e a olhar além deles à procura das simples mas profundas recompensas da criação de seu filho - os sorrisos, os estágios de desenvolvimento -, ensina os pais a terem equilíbrio necessário... Pode muito bem acontecer de os pais apaixonarem-se pelo bebê à primeira vista, mas a permanência deste amor é um processo de aprendizagem - de aprender a conhecer a si mesmo, bem como o bebê (p.14).

\section{Método}

Este texto apresenta o significado da maternidade para três jovens, abrigadas com seus filhos em uma instituição para adolescentes gestantes ou mães em situação de risco físico, emocional e/ou social, no município de São Paulo. Trata-se de um recorte de uma pesquisa de mestrado realizada no Instituto de Psicologia da Universidade de São Paulo, (USP) que teve como objetivo principal compreender como essas "meninas mães", que tiveram diversas experiências de violência em suas trajetórias, exer- 
cem a maternidade, se conseguem ou não oferecer um cuidado suficientemente bom para seus filhos, acolhendo suas angústias e suprindo suas necessidades tanto físicas quanto emocionais.

Os encontros com as participantes foram realizados no ano de 2008, entre os meses de julho e outubro; cada encontro foi marcado individualmente, em dias e horários diferentes para cada participante.

Essa pesquisa foi norteada pela escuta psicanalítica, que tem em sua essência a busca pela compreensão dos sentidos das manifestações humanas. Para dialogar com os conteúdos encontrados, foi usada como referência a teoria de Donald W. Winnicott.

O estudo foi aprovado pelo Comitê de Ética em Pesquisa do Instituto de Psicologia da USP, Protocolo n² 2008.062, em 09/02/2009, e todos os participantes assinaram um Termo de Consentimento Livre e Esclarecido antes de sua inclusão na amostra.

Foram realizados com cada dupla mãe-filho cinco encontros, com aproximadamente uma hora de duração. Nesses encontros, alguns temas abordados foram definidos previamente para que determinados conteúdos, relevantes para o objetivo central, fossem alcançados. No entanto, esses temas foram tratados de forma singular com cada participante, não havendo preocupação quanto a sua ordem. Os assuntos foram sendo inseridos à medida que se encontrava espaço para a colocação das perguntas; buscou-se, assim, conhecer a:

a) Relação com a mãe e a família: qual referência a adolescente tem a respeito dos cuidados maternos; como era a relação com os demais membros da família; que lembranças relacionadas à experiência com os pais ela tem da infância;

b) Vivência da gestação e da maternidade: sentimentos e emoções diante da gravidez (se ela foi ou não planejada); ganhos e perdas diante da experiência da maternidade, sentimentos em relação à maternidade;

c) Experiência com a violência: verificar a existência e o grau de violência na história pessoal e como elas aparecem atualmente, e d) Relação com o filho: como percebe seu filho(a); quais suas preocupações em relação a ele(a), se há alguma dificuldade nos cuidados com ele.

\section{Resultados e Discussão}

Adriana 17 anos, mãe de André, 3 anos, estava sendo assistida pela Instituição desde 2003. Antes de ir para o abrigo de jovens mães, morava na casa da juventude (abrigo da mesma entidade para adolescentes em situação de risco). Adriana fugiu de casa aos doze anos, vindo para a capital paulista para fugir da violência de seu pai, que agredia fisicamente tanto ela quanto os irmãos e que tentou abusar dela sexualmente.

Adriana planejou sua gravidez. Para ela, um filho significava ter mais estabilidade e manteria sua relação com o pai de André. Em nosso primeiro encontro, ela contou que conheceu o pai de André, um jovem de quinze anos de idade, no primeiro abrigo onde morou. Apaixonou-se por ele, imaginava que nunca mais iria gostar de outra pessoa. Ela achava que se eles tivessem um filho estariam unidos para sempre, nunca mais se separariam. Dizia também que sentia vontade de ser mãe e ter uma família. No entanto, no momento em que a pesquisa foi realizada, ela e o pai de André já não mantinham nenhum tipo de contato.

André nasceu no quinto mês de gestação com 600 g; ficou quatro meses na Unidade de Terapia Intensiva do hospital. Ela disse que algumas enfermeiras Ihe falavam que ela era muito jovem e que poderia ter outros filhos, "isso é coisa que se fale..." [sic]. Mas ela não aceitava, contou que se sentia muito triste e passava o dia todo no hospital, voltando somente à noite para o abrigo. Durante os quatro meses em que o filho ficou internado, ela faltou um único dia, um domingo, em que não conseguiu condução para ir ver o filho.

A realidade logo se apresentou à Adriana. As demandas de um bebê e as mudanças que se estabelecem na rotina de quem passa a desempenhar a função de cuidadora chegaram de forma intensa e inesperada em sua vida. Ela apresentou um quadro de depressão pós-parto, segundo a coor- 
denadora do abrigo, que também afirmou que, apesar de todas as dificuldades, Adriana não deixou de ir ao hospital. Foi uma dura realidade para uma menina de 14 anos, que ainda necessitava ser cuidada, mas que estava sendo solicitada a cuidar.

Perguntei a ela se ser mãe era como ela imaginava quando desejou engravidar. Ela disse que sofreu muito quando André nasceu, pois nunca imaginou que teria um filho prematuro: "ele não era normal, era muito pequeno" [sic]. Na época dos encontros, André apresentava atrasos cognitivos e motores visíveis. Verbalizava poucas palavras, não tinha controle esfincteriano, tinha baixa estatura e estava visivelmente desnutrido. Apesar de estar com três anos, aparentava ter aproximadamente um ano e meio. Quase não recebia estímulos. Adriana ainda não havia conseguido vaga na creche e ela própria tentava fazer o básico: dar-lhe banho, alimentá-lo, trocá-lo. Brazelton (1988), em seu trabalho sobre a formação do apego dos pais aos filhos prematuros, afirma que:

Não se admira que uma mãe, em tal situação, queira fugir, esconder-se ou proteger-se sob uma depressão - ou alienar-se para se proteger de ter que cuidar desse bebê... O que me surpreende não é que muitas mães e pais devam defender-se contra tal sentimento avassalador, mas que possam superar estes sentimentos e começar tudo novamente, vinculando-se ao bebê que sentem ter posto em perigo (p.74).

Adriana oscilava constantemente na relação com o filho. Ao mesmo tempo em que a experiência da maternidade se revelou como a possibilidade de ter um objetivo na vida, ter alguém por quem valha a pena lutar, voltar a estudar, voltar a desejar, exigia dela uma entrega que ela ainda não estava pronta para vivenciar.

Reis e Monteiro (2007) apontam em sua pesquisa que, na visão dos adolescentes, o motivo que leva a uma gravidez nessa fase da vida é o sentimento de solidão, em primeiro lugar, e as brigas ou tristezas com a família em segundo lugar. Para o grupo exclusivamente das meninas, a vontade de ter sua própria família é um fator relevante e apa-

522 rece como principal razão.
Izabela, 16 anos, mãe de Helena, 1 ano e 5 meses, era uma jovem obesa, e, segundo a coordenadora do abrigo, era muito agressiva e apresentava problemas de relacionamento com as demais meninas, permanecendo grande parte do tempo isolada. Izabela apresentava uma grande labilidade emocional e sintomas depressivos. Durante nossos encontros, muitas vezes, permanecia calada. Ficava com os olhos cheios de lágrimas, mas não queria ou não conseguia dizer o que estava pensando ou sentindo. Mostrava um grande sofrimento, mas não conseguia expressá-lo ou aceitar ajuda.

Contou que não planejou a gravidez e que engravidou na primeira vez que se relacionou sexualmente com o pai de Helena. Sobre a maternidade, dizia que ainda não sabia se queria ser mãe. "É muita coisa pra uma pessoa só!" [sic]. Perguntei se ela já havia pensado em se separar de Helena, e ela disse que pensava nisso todos os dias. Em alguns momentos, ela demonstrava que não conseguia cuidar nem de si mesma: como poderia ser responsável pela vida e o bem-estar de outra pessoa?

Izabela revelou sua impaciência e sua insatisfação com as mudanças que a maternidade trouxe para sua vida. Falava que Helena tomava todo o seu tempo e que em qualquer lugar que ela fosse tinha que levar a filha. Ela não demonstrava, naquele momento, estar disponível para atender às demandas da filha. O que chamava a atenção é que mesmo assim ela não desistiu. A maternidade trouxe alguns ganhos à Izabela, uma vez que, mesmo sem saber o porquê, não abandonou sua filha. Quando questionei se havia algo de bom na maternidade, ela disse que era ver Helena crescer. Helena é sua criação e, por esse motivo, ela não poderia deixar sua filha. Ela precisava da filha para sentir-se capaz e recuperar sua potência. Além disso, Helena aceitava Izabela e permitia-Ihe sentir-se querida e importante. Ela não era mais uma na vida de Helena.

A ausência ou a fragilidade dos laços afetivos estabelecidos pela adolescente e sua família ou nas primeiras relações traz a sensação de solidão e desamparo. Rosa, Reis e Tanaka (2007) consideram que, em alguns casos, pode haver uma repetição da história familiar e a tentativa, por parte da mãe, 
de transferir para o filho imaginado suas próprias necessidades, sonhando oferecer a ele aquilo de que ela pressupõe ter sido privada, como carinho, proteção ou uma família. A busca por uma relação de maior estabilidade é proeminente, o que não quer dizer que ao encontrá-la a adolescente estará apta a investir nela, uma vez que estabelecer e reconhecer um laço afetivo e a dependência do outro é extremamente aterrorizador pelo temor da perda ou da intrusão.

Silva e Salomão (2003) constataram, em sua pesquisa, que $72 \%$ das mães de adolescentes que haviam engravidado também foram mães adolescentes e que, ainda assim, reprovavam o comportamento da filha. Percebe-se, então, que a reprodução de algumas condutas não aparece relacionada somente à transmissão de valores e ao papel da mulher ligado à maternidade, que se configuraria com a transmissão dos legados intergeracionais mas também a outros componentes não tão acessíveis à consciência. A perpetuação de uma condição de desamparo na fase adolescente, a busca por uma relação afetiva genuína e a ausência da figura masculina que exerça sua função parental podem exemplificar alguns desses legados transgeracionais que têm representação particular dentro da história de cada família (Correa, 2000).

Bia, 17 anos, mãe de Gabriel, 10 meses, mantinha contato com a mãe, embora não fosse frequente. Além dela, outras duas irmãs estavam no abrigo, mesmo sem ter filhos; moravam lá a pedido de Bia. Ela e as irmãs passaram a fugir de casa após as surras que levavam da mãe. Bia tinha cerca de 13 anos nessa época. Ela conta que sua mãe começou a agredi-las quando se separou de seu pai, depois de surpreendê-lo tentando abusar de Bia. Ela e suas irmãs já haviam passado por muitos abrigos, mas sempre fugiram de todos. Fugiam e ficavam na rua, onde permaneciam juntas.

Bia não planejou sua gravidez, mas também nunca se preveniu. Ela contou que conhecia o pai de Gabriel desde criança e quando ela e as irmãs foram morar com a avó eles começaram a namorar; depois de cinco meses, ela engravidou. Perguntei o motivo de não se prevenir e ela disse que nem pensava nisso. Perguntei como ela descobriu que estava grávida e ela contou que foi o pai de Gabriel que descobriu e que ele trouxe remédio para ela abortar o filho, mas ela se recusou. Segundo Bia, ela nunca pensou em abortá-lo; depois disso, o rapaz não olhou mais para ela e Bia também não quis mais encontrá-lo.

Na história de meninas que vivem em abrigos, a ruptura dos laços e a perda de referência são vivências bastante presentes. Há um imenso vazio e lacunas que se abrem, relações construídas pela falta, pela experiência dolorosa, pela carência de uma experiência de afeto estruturante na constituição do ego. Um filho representa, muitas vezes, a esperança para resgatar a experiência de afeto perdida. Algumas meninas, por meio da experiência da gestação, que é um momento de maior sensibilidade e regressão, poderão, com ajuda profissional, elaborar sua própria história, seus fantasmas pessoais e conteúdos transmitidos entre as gerações que, na impossibilidade de serem ditos, são mantidos no inconsciente familiar.

A construção de uma família e a experiência da parentalidade vão ser buscadas repetidas vezes para superar o abandono anterior, o vazio, a ausência de relações de afeto. Algumas adolescentes desejam ter um bebê, e muitos sonhos são formados a partir dessa decisão. São fantasias criadas a partir da necessidade de um sentimento de pertencimento, da necessidade de sentir-se investido de afeto por outra pessoa. Há espaços no mundo interno desses jovens que precisam ser preenchidos; vazios criados pelo mundo adulto e pela sociedade que falha em dar continência às demandas dos indivíduos e as suas necessidades.

\section{Considerações Finais}

A necessidade do indivíduo de "sustentação" (holding) se estende ao longo de sua vida, embora varie quanto ao seu grau de dependência e pela maneira como se apresenta. O envolvimento afetivo dos pais ou de alguém que substitua essa função, a empatia, a reciprocidade e a segurança são condições indispensáveis para que o ser humano se desenvolva e sinta-se compromissado com seus semelhantes. Adriana, Izabela e Bia, sujeitos desta pesquisa, representam uma pequena amostra de 
um grande grupo de pessoas que buscam, por meio de uma relação de afeto genuíno, restabelecer a confiança no meio e em seus semelhantes.

Essas meninas fazem parte de uma população que não está inserida em um ambiente familiar seguro, não tem acesso a uma educação de qualidade, não viu seus pais serem bem sucedidos profissionalmente e vive um dia após o outro, sem muitos planos, tamanha a dificuldade em projetar para si um futuro promissor, ou seja, é uma parcela significativa da população em que esses elementos básicos não estão presentes. Pensar no significado da gravidez na fase da adolescência, para elas, não é pensar de maneira genérica na gravidez na adolescência. Ainda que a gravidez na adolescência aconteça em todas as classes sociais e, dessa forma, não seja esse um acontecimento restrito às meninas das classes sociais mais baixas, essa experiência tem um significado distinto para quem passa por tantas privações, inclusive a de ser considerado e tratado como um cidadão e ter um papel social. É a experiência da maternidade que permite a essas meninas mães que elas tornam-se visíveis ao mundo por meio de uma função nova e extremamente significativa: o papel de ser mãe. A maternidade é também a oportunidade de tornarem-se pessoas melhores, um motivo novo para buscar o que cada uma tem de mais verdadeiro e humano. No entanto, essa não é uma tarefa simples para quem sofreu tantas violências ao longo de sua trajetória.

A assistência às jovens mães representa um cuidado importante para que elas possam assumir a maternidade e conquistar a confiança em si e em suas habilidades. Assisti-las quer dizer apoiá-las e oferecer-lhes sustentação para suas angústias, medos e dúvidas, por meio de intervenções diretas que visem ao acompanhamento da gestação e dos primeiros anos de vida de seu filho. A capacidade de se vincular a seu filho e de cuidar adequadamente dele não deve ser algo colocado previamente em dúvida. Isso, em muitas situações, acaba por gerar preconceito e aumentar o estigma de que elas não possuem capacidade para se responsabilizar por uma criança. Esse é um olhar que contribui para uma postura passiva, submissa e marginal.

Mais uma vez ressalta-se que não se trata 524 de ignorar as possíveis dificuldades que podem sur- gir na execução da função materna em jovens mães. Entretanto, mais do que considerar a idade biológica da mãe, deve-se levar em conta sua história pessoal e suas condições emocionais para realizar a maternagem, que podem ser precárias tanto na fase adolescente quanto na fase adulta.

Desse modo, para que a maternidade não se torne um peso na vida dessas jovens, é preciso que elas recebam ajuda e possam integrar e conciliar os diferentes momentos e necessidades. A negação de qualquer um desses aspectos é nociva para a adolescente em si e para a relação com seu filho. Garantir espaços onde ela possa encontrar o que precisa para suprir suas demandas auxilia seu processo de amadurecimento.

Tanto a violência estrutural, aquela que envolve os aspectos históricos, econômicos e culturais, quanto as outras formas de violência (física, psicológica, sexual e a negligência) interferem no desenvolvimento do processo de subjetivação, do ser humano, que passa a ter que viver concretamente, no corpo e nas atitudes, suas angústias, medos, prazeres. O sentimento de confiança não se estabelece e o indivíduo organiza seu Eu de forma insegura, o que torna seu viver de forma criativa um desafio.

A violência impede que o homem se torne um ser humanizado. O sentimento de entrega que existe na relação mãe-filho torna-se um desafio diante da falta de sustentação do ambiente e da insegurança interna do indivíduo. De uma geração a outra, o sentimento de insegurança é transmitido, assim como a necessidade de provocar o ambiente para saber se é possível confiar nele ou não. O que não se pode esquecer é que essa situação revela um pedido de ajuda, que se for percebido a tempo pode modificar a maneira pela qual as relações vem sendo construídas. Adriana, Izabela e Bia ainda têm esperança, assim como tantas outras pessoas que estão à espera de um encontro genuíno com o outro, com alguém que se torne significativo em suas vidas. É importante que os profissionais da área e os cidadãos no geral não percam a oportunidade de auxiliar as pessoas em seu processo de amadurecimento, na reconstrução de suas histórias e no encontro com sua humanidade. 


\section{Referências}

Badinter, E. (1985). Um amor conquistado: o mito do amor materno. Rio de Janeiro: Nova Fronteira.

Brazelton, T. B. (1988). O desenvolvimento do apego: uma família em formação. Porto Alegre: Artes Médicas.

Correa, O. B. R. (2000). Eclosão dos vínculos genealógicos e transmissão psíquica. In O. B. R. Correa (Org.), Os avatares da transmissão psíquica. São Paulo: Escuta.

Dolto, F. (1984). A gênese do sentimento materno: esclarecimento psicanalítico da função simbólica feminina. In F. Dolto. No jogo do desejo: ensaios clínicos. Rio de Janeiro: Zahar.

Gama, S. G. N., Szwarcwald, C. L., \& Leal, M. C. (2002). Experiência de gravidez na adolescência, fatores associados e resultados perinatais entre puérperas de baixa renda. Cadernos de Saúde Pública, 18(1), 153-161. Recuperado em maio 14, 2009, de www.scielo.br

Goldenberg, P., Figueiredo, M. C. T., \& Silva, R. S. (2005). Gravidez na adolescência, pré-natal e resultados perinatais em Montes Claros, Minas Gerais, Brasil. Cadernos de Saúde Pública, 21(4), 1077-1086.

Gontijo, D. T., \& Medeiros, M. (2008). Tava morta e revivi: significado de maternidade para adolescentes com experiência de vida nas ruas. Cadernos de Saúde Pública, 24(2), 469-472.

Lebovici, S. (2004). Diálogo Letícia Solis-Ponton e Serge Lebovici. In L. Solis-Ponton (Org.), Ser pai, ser mãe parentalidade: um desafio para o terceiro milênio. São Paulo: Casa do Psicólogo.

Oliveira, N. R. (1999). Perfis de grávidas de mães adolescentes: estudo psicossocial de mães adolescentes usuárias de um serviço público pré-natal e maternidade (Tese de doutorado não-publicada). Universidade de São Paulo.

Paiva, M. L., \& Gomes, I. C. (2008). A transmissão da vida familiar. In I. C. Gomes, (Coord.), Família: diagnóstico e abordagens terapêuticas. Rio de Janeiro: Guanabara Koogan.

Reis, A. O. A., \& Monteiro, N. R. (2007). Sexualidade e procriação na ótica de jovens de periferias sociais e urbanos. Revista Brasileira de Crescimento e Desenvolvimento Humano, 17(2), 54-63. Recuperado em novembro 13, 2008, de www.scielo.br

Rosa, A. J., Reis, A. O. A., \& Tanaka, A. C. A. (2007). Gestações sucessivas na adolescência. Revista Brasileira de Crescimento e Desenvolvimento Humano, 17(1), 165-172. Recuperado em maio 14, 2009, de www. scielo.br

Sabroza, A. R., Leal, M. C., Souza, P. R., Jr., \& Gama, S. G. N. (2004). Algumas repercussões emocionais negativas da gravidez precoce em adolescentes do Município do Rio de Janeiro (1999-2001). Cadernos de Saúde Pública, 20(Supl. 1), S130-S137.

Silva, D. V., \& Salomão, N. M. R. (2003). A maternidade na perspectiva de mães adolescentes e avós maternas dos bebês. Estudos de Psicologia, 8(1), 135-145. Recuperado em maio 14, 2009, de www.scielo.br

Suzuki, C. M., Ceccon, M. E. J., Falcão, M. C., \& Vaz, F. A. C. (2007). Análise comparativa da freqüência de prematuridade e baixo peso entre filhos de mães adolescentes e adultas. Brasileira de Crescimento e Desenvolvimento Humano, 17(3), 95-103. Recuperado em maio 14, 2009, de www.scielo.br

Winnicott, D. W. (1990). Teoria do relacionamento paterno-infantil. In D. W. Winnicott. O ambiente e os processos de maturação: estudos sobre a teoria do desenvolvimento emocional ( $3^{\mathrm{a}} \mathrm{ed}$.). Porto Alegre: Artes Médicas. (Originalmente publicado em 1960).

Winnicott, D. W. (2000). A preocupação materna primária. In D. W. Winnicott. Da pediatria à psicanálise: obras escolhidas. Rio de Janeiro: Imago. (Originalmente publicado em 1958).

Winnicott, D. W. (2006). A mãe dedicada comum. In D. W. Winnicott. Os bebês e suas mães ( $3^{a}$ ed.). São Paulo: Martins Fontes. (Originalmente publicado em 1966).

Yazlle, M. E. H. (2006). Gravidez na adolescência. Revista Brasileira de Ginecologia e Obstetrícia, 28(8), 443-445.

Recebido em: 22/6/2012

Versão final em: 14/9/2012

Aprovado em: 7/12/2012 
